\title{
EXPERIMENTAL INVESTIGATIONS ON IMPACT TOUGHNESS AND SHEAR STRENGTH OF NOVEL LEAD FREE SOLDER ALLOY Sn-1Cu-1Ni-XAg
}

\author{
Jayesh S, Jacob Elias
}

\begin{abstract}
Lead is known to be banned in alloy making, highlighting toxicity concerns and environmental legislations. Researchers and scholars around the globe were in immediate search of new lead free solder alloys which could potentially replace the old $\mathrm{Sn}-\mathrm{Pb}$ alloy. In this comprehensive study, shear strength and impact toughness tests were conducted on $\mathrm{Sn}-1 \mathrm{Cu}-1 \mathrm{Ni}$ when different amounts of $\mathrm{Ag}(0.25,0.5,0.751$ $\%$ by wt.) is added. Shear strength test is tested using micro force test system. Impact toughness test is analyzed using Charpy impact test set up by calculating the energy difference before and after impact. The study reveals that, Ultimate shear stress increased from $19 \mathrm{MPa}$ to $21.3 \mathrm{MPa}$. Yield strength increased from 27.4 MPa to 29.7 Mpa. Impact toughness of the alloys increased from $9.4 \mathrm{~J}$ to $10.1 \mathrm{~J}$. Thus, $\mathrm{Sn}-1 \mathrm{Cu}-1 \mathrm{Ni}-1 \mathrm{Ag}$ is found to have improved shear strength and impact toughness than $\mathrm{Sn}-1 \mathrm{Cu}-1 \mathrm{Ni}$.
\end{abstract}

Keywords: solder alloy; lead free; impact toughness; shear strength

\section{INTRODUCTION}

Soldering basically is a metallurgical joining process which is done without melting the parent metals. The solder alloy in the molten liquid form will wet the surface of the parent metals, thereafter resulting in a bond formation between the work pieces once solidification sets [1]. In electronics packaging industry, the electronic components are soldered onto the printed circuit board (PCB) using the solder alloy. Therefore the solder alloy acts as a connection device between the electronics components and the circuit on the PCB [2]. Product reliability, mechanical properties, electrical properties, cost of the solder alloy etc. are some vital inputs that involve significant analysis. The failure of the solder alloy can lead to the failure of the functioning of the electronic package which may in turn make the device useless as a whole [3]. Electronic packages are used all round the world, especially in mobile industries, laptop industries, avionic industries, marine electronics etc. Hence, reliability of the solder alloy holds high significance. $\mathrm{Sn}-\mathrm{Pb}$ alloy has improved properties like low melting point $\left(183^{\circ} \mathrm{C}\right)$, good wettability on $\mathrm{Cu}$, good hardness, good ductility, good workability, good availability, low cost etc. Due to the inherent toxicity of lead, the usage of lead has been banned from alloy making. Environmental legislations like RoHS (Restrictions on Hazardous Substance), WEEE (Waste Electrical and Electronic Equipment) sought the ban of Lead in electronic packages.

Jayesh S: Department of Mechanical Engineering, School of Engineering, Cochin University of Science and Technology, Kerala, India

Jacob Elias: Department of Mechanical Engineering, School of Engineering, Cochin University of Science and Technology, Kerala, India 
Following this many countries also followed the legislations [4]. This led to the necessity of the need for new lead-free solder alloys which can replace the $\mathrm{Sn}-\mathrm{Pb}$ solder alloy. Infact, the toxic nature of lead is not the only reason for search for lead-free solder joints. As the transistor density increases the solder joint pattern also changes. The pitch of this solder arrangement will be in trouble if $\mathrm{Sn}-\mathrm{Pb}$ solder alloy is used in dense electronic packages. Behavior of customer and economy is yet another reason. Another reason is the need for high temperature solder alloys.

Research teams have started developing new lead free solder alloy which can be used as a replacement for the $\mathrm{Sn}-\mathrm{Pb}$ alloy. $\mathrm{Sn}-\mathrm{Ag}-\mathrm{Cu}$ is found to alloy better with good properties. SAC105, SAC305, SAC405 are some examples. But the amount of Ag in SAC alloys will add to the cost. Besides the element costs, high patent costs also result. Many compositions were discovered as a replacement for $\mathrm{Sn}-\mathrm{Pb}$ alloy. Some major compositions include Sn-Bi-Ag [5], Sn-Bi [6], Sn-Zn [7], Sn-Ag-Cu [8, 9], Sn-Cu [7], Sn-Zn-Bi [5]. The effect of addition of $\mathrm{Ag}$ into $\mathrm{Sn}-0.5 \mathrm{Cu}-1 \mathrm{Bi}$ (SCB305) and $\mathrm{Sn}-1 \mathrm{Cu}-1 \mathrm{Ni}$ (SCN110) were tracked, studied and the mechanical properties such as melting temperature, hardness and contact angle were found to be improved $[10,11]$. Studies on the reliability under random vibrations were also studied [12]. The cost also was less when compared to the SAC alloys. In this paper, impact toughness and shear strength of the SCN110 are studied while Ag is added into it in $0.25,0.5,0.75,1 \%$ by wt.

\section{EXPERIMENT}

\section{Sample preparation}

Solder alloy specimens were intended and produced from pure metals which are in powder form. The composition and allocated codes are provided in the table 1. Powder form of pure metals of $\mathrm{Sn}, \mathrm{Cu}, \mathrm{Ni}$ and $\mathrm{Ag}$ are initially weighed in proper weight proportions. These were melted in induction furnace at more than $900^{\circ} \mathrm{C}$ for 45 minutes. These were then transferred to cylindrical molds. Five samples were made using the above procedure. The samples were quenched and were kept at room temperature for one day. The first sample was made using $\mathrm{Sn}, \mathrm{Cu}$ and $\mathrm{Ni}$ according to the composition shown in the Table 1 . In the next four samples $\mathrm{Ag}$ is added in four different proportions $(0.25,0.5,0.75$, and $1 \%$ by wt.). These samples were obtained in the form of disc shapes. The samples are then undergone through visual inspection to ensure that the surface of these samples were free from damages[11].

\section{Shear strength}

The samples were produced as discussed in the sample preparation section. Five samples of each alloy were tested in the similar condition. For shear test to be conducted, micro lap shear solder joint samples were made. The same is shown in a schematic way in Figure 1. All the five samplew set were ground using SiC paper, followed by polishing to eliminate any excess solder at the boundaries. Micro-force test system was used to conduct the shear strength test. A software was used to control the system. Test data are collected with the aid of this software. The shear strength tests were conducted on the five samples at room temperature. $5 \times 10^{-4} / \mathrm{S}$ is the strain rate used. The results were averaged among the five data. 


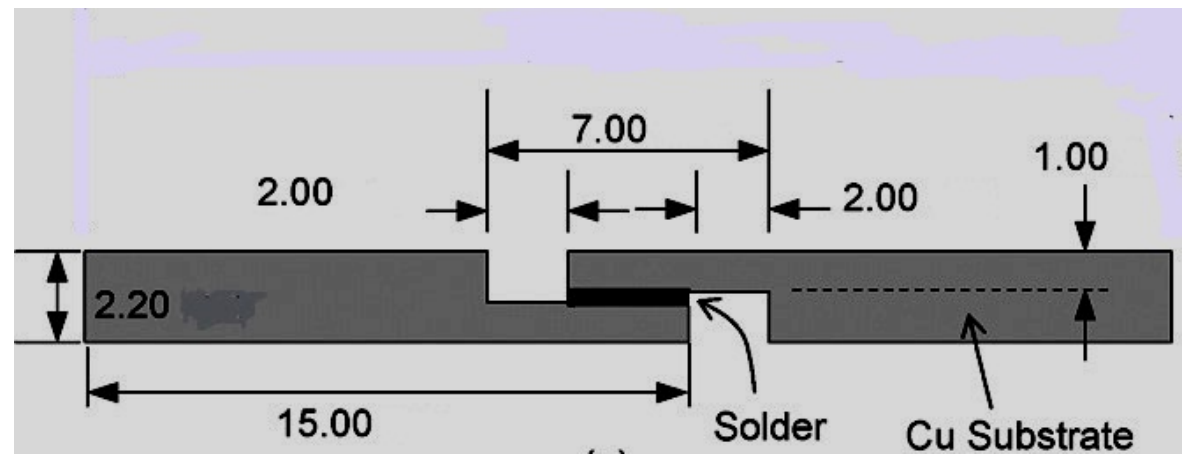

Fig.1. The samples for shear test.

\section{Impact toughness test}

In order to conduct the impact test, Charpy impact tests with pendulum type impact tester were used. The pendulum effective weight was $21 \mathrm{Kg}$. Five specimens of each alloy were prepared with dimensions $70 \mathrm{~mm}$ long $\mathrm{x} 5 \mathrm{~mm}$ wide $\mathrm{x} 5 \mathrm{~mm}$ thick. The schematic drawing given in the figure 2 shows the setup and the principle of the Charpy impact test. The pendulum is lifted to a height $\mathrm{H}$. This is considered as the initial position. E1 is the initial potential energy. Then the pendulum is allowed to swing and hit the specimen. After hitting the specimen it rises to a height of H1. E2 is the energy at this stage and it is considered as the final energy. During hitting the specimen, some amount of energy $E$ is absorbed by the specimen. The impact absorbed energy was obtained. The same procedure is repeated for all the five samples. The test data obtained is then averaged. The data regarding the absorbed energy obtained during the test helps in analyzing the impact toughness of the alloys.

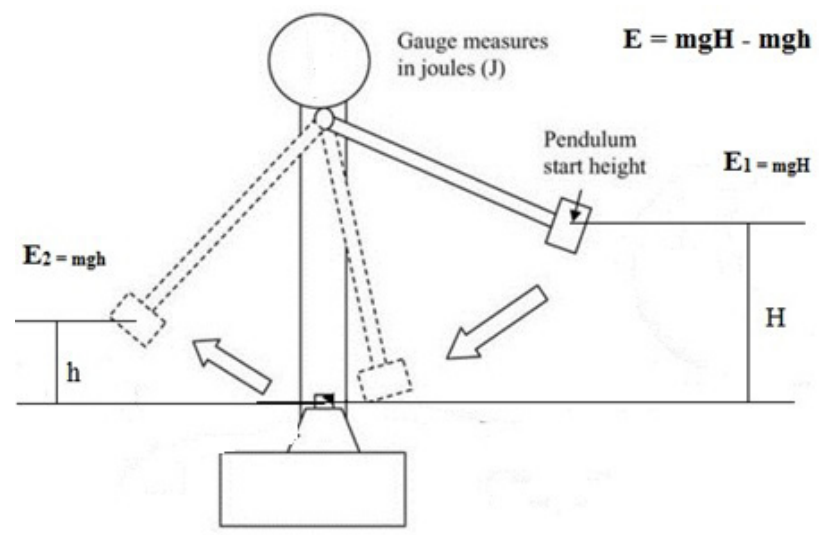

Fig.2. Impact toughness using Charpy apparatus (schematic representation). 


\section{Mechanical properties of the alloy}

Mechanical properties of SCN110 alloy were tabulated [18]. Variations taking place while adding $\mathrm{Ag}$ in $0.25,0.5,0.75,1 \%$ by wt. were also investigated in the study. The melting temperature, contact angle and the hardness values are given in the table 1 .

Tab.1. Melting temperature, contact angles and hardness of the alloys.

\begin{tabular}{|l|c|c|c|}
\hline \multicolumn{1}{|c|}{ Solder Alloy } & $\begin{array}{c}\text { Melting } \\
\text { Temperature }\left[{ }^{\circ} \mathrm{C}\right]\end{array}$ & $\begin{array}{c}\text { Contact } \\
\text { angle }\left[{ }^{\circ}\right]\end{array}$ & $\begin{array}{c}\text { Hardness } \\
{[\mathrm{HV}]}\end{array}$ \\
\hline Sn-1Cu-1Ni & 232.2 & 36.75 & 16.1 \\
\hline Sn-1Cu-1Ni-0.25Ag & 231.2 & 27.54 & 16.3 \\
\hline Sn-1Cu-1Ni -0.5Ag & 230.1 & 26.44 & 17.5 \\
\hline Sn-1Cu-1Ni -0.75Ag & 229.4 & 24.12 & 18.7 \\
\hline Sn-1Cu-1Ni -1Ag & 228.4 & 22.87 & 19.2 \\
\hline
\end{tabular}

\section{RESULTS AND DISCUSSION}

\section{Shear strength}

Apart from the electrical properties, the mechanical properties of the solder alloys are very important, citing the fact that the electronic package should be reliable throughout its operational life. Material's ability to resist forces that can cause the internal structure of the material to slide against itself is termed as shear strength. Shear strength tests of the samples with different amount of Ag are conducted using the method explained in the above section. The results of the analysis are noted and are given in the table 2 . Following strengthening mechanisms can be identified as the reason for improvement in the mechanical properties. Geometrically similar dislocations generated which accommodate the elastic modulus and thermal modulus mismatch. The results obtained are shown in the Figure 3. The dispersion hardening with the addition may be a reason for the increase in the shear strength. With the addition of Ag, the density of the alloy is also found to be increasing slightly. The ultimate shear stress of $\mathrm{Sn}-1 \mathrm{Cu}-1 \mathrm{Ni}$ is found to be increased by $8.3 \%$ by wt. with $1 \%$ addition of $\mathrm{Ag}$.

Tab.2. Shear strength results of the alloys.

\begin{tabular}{|l|c|c|}
\hline \multicolumn{1}{|c|}{ Solder Alloy } & $\begin{array}{c}\text { Ultimate Shear } \\
\text { stress [MPa] }\end{array}$ & $\begin{array}{c}\text { Yield Strength } \\
{[\mathrm{Mpa}]}\end{array}$ \\
\hline Sn-1Cu-1Ni & 27.4 & 19 \\
\hline Sn-1Cu-1Ni-0.25Ag & 27.2 & 19.1 \\
\hline Sn-1Cu-1Ni $-0.5 \mathrm{Ag}$ & 28.3 & 20.4 \\
\hline Sn-1Cu-1Ni $-0.75 \mathrm{Ag}$ & 29.2 & 21.1 \\
\hline Sn-1Cu-1Ni $-1 \mathrm{Ag}$ & 29.7 & 21.3 \\
\hline
\end{tabular}




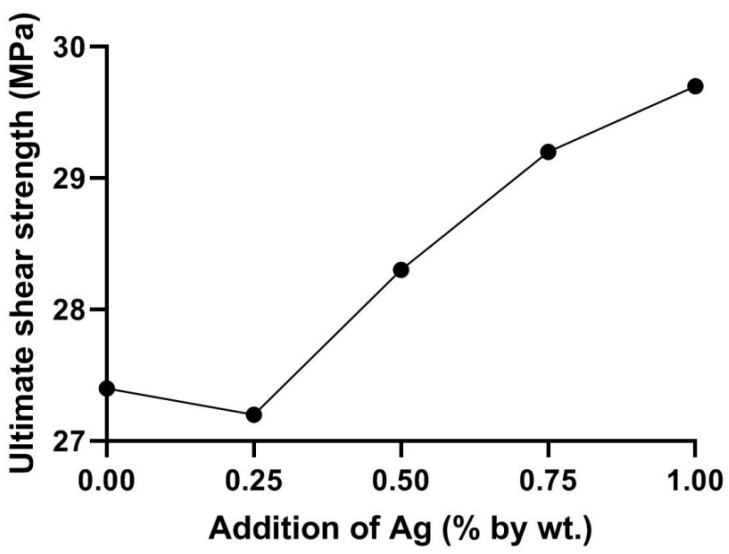

Fig.3. Ultimate shear strength of the alloys.

\section{Impact toughness}

Impact toughness is a fundamental material property required to measure the performance of solder alloys. The impact toughness is directly proportional to the energy absorbed by the alloy. The crashworthiness of the solder alloy is an important property. Impact strength can be defined as the measure of energy that a specimen can absorb during the conduction of the test before fracturing. During fracturing it undergoes rapid rate of deformation. Impact toughness tests for all the samples with different amount of Ag are conducted using charpy impact test explained in the previous section. The energy absorbed by the test specimen gives idea about the impact toughness. The results obtained are given in the table 3. The results obtained are shown in the figure 4. The samples which are able to absorb more impact energy during the conduction of impact test will be considered as materials having more impact toughness. The microstructure also will have close relation with the impact toughness. Charpy test is the apt test for determining the impact toughness of the solder alloy. Even if we are using large test specimens for the test when compared to the solder joints, the strain rate experiencing in the both cases are matching. The impact toughness of $\mathrm{Sn}-1 \mathrm{Cu}-1 \mathrm{Ni}$ is found to be increased by $3.1 \%$ with the addition of $1 \%$ by wt. Ag.

Tab.3. Impact toughness test results of the alloys.

\begin{tabular}{|l|l|}
\hline \multicolumn{1}{|c|}{ Solder Alloy } & \multicolumn{1}{c|}{ Impact Toughness [J] } \\
\hline $\mathrm{Sn}-1 \mathrm{Cu}-1 \mathrm{Ni}$ & 9.4 \\
\hline $\mathrm{Sn}-1 \mathrm{Cu}-1 \mathrm{Ni}-0.25 \mathrm{Ag}$ & 9.7 \\
\hline $\mathrm{Sn}-1 \mathrm{Cu}-1 \mathrm{Ni}-0.5 \mathrm{Ag}$ & 9.8 \\
\hline $\mathrm{Sn}-1 \mathrm{Cu}-1 \mathrm{Ni}-0.75 \mathrm{Ag}$ & 9.9 \\
\hline $\mathrm{Sn}-1 \mathrm{Cu}-1 \mathrm{Ni}-1 \mathrm{Ag}$ & 10.1 \\
\hline
\end{tabular}




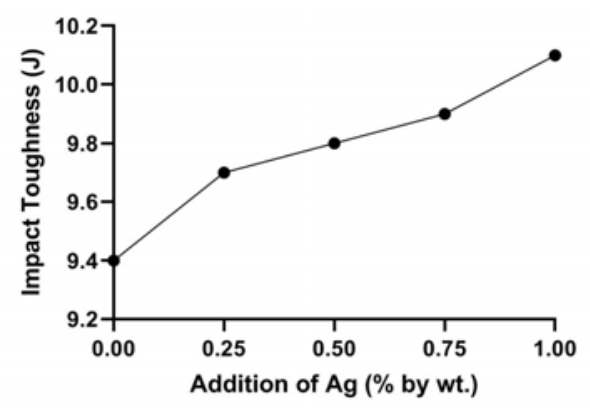

Fig.4. Impact toughness test results.

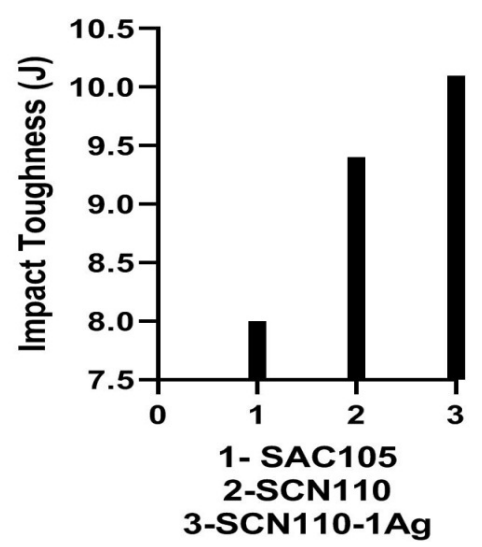

Fig.6. Impact toughness comparisons.

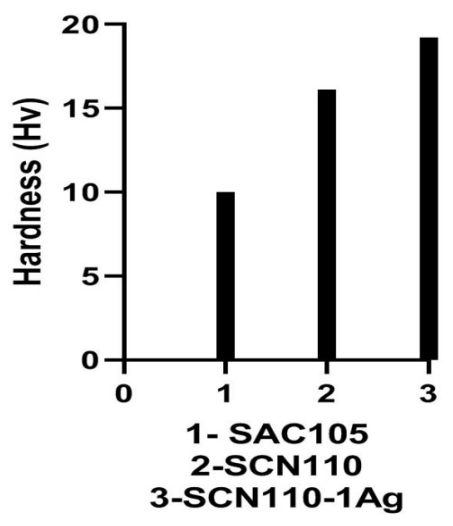

Fig.5. Hardness comparison.

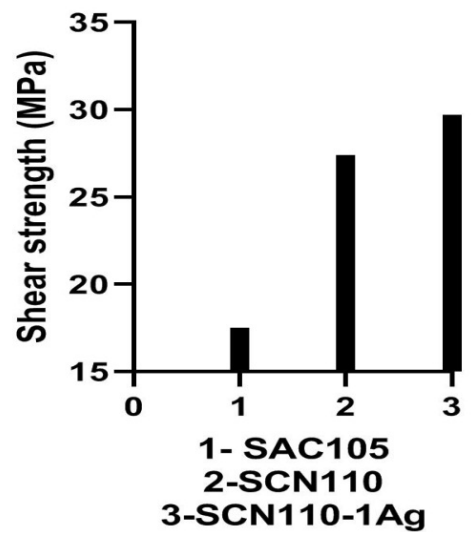

Fig.7. Shear strength comparisons.

\section{CONCLUSION}

The lead free solder alloys are prepared in the induction furnace where $\mathrm{Sn}, \mathrm{Cu}, \mathrm{Ni}$ and Ag are available in the form of powder. The chemical composition were verified. Shear strength test and impact toughness test were carried out first on $\mathrm{Sn}-1 \mathrm{Cu}-1 \mathrm{Ni}$ and then on Sn-1Cu-1Ni-xAg ( $x=0.25,0.5,0.75,1 \%$ by wt.) using micro force test system and Charpy impact testing apparatus. Ultimate shear stress is found to be increased from $19 \mathrm{MPa}$ to 21.3 MPa. Yeild strength is found to be increased from 27.4 MPa to 29.7 MPa. The ultimate shear stress of $\mathrm{Sn}-1 \mathrm{Cu}-1 \mathrm{Ni}$ is found to be increased by $8.3 \%$ by wt. with $1 \%$ addition of $\mathrm{Ag}$. This alloy ( $\mathrm{Sn}-1 \mathrm{Cu}-1 \mathrm{Ni}-1 \mathrm{Ag})$ is found to be having good mechanical properties (melting temperature, contact angle and hardness) with the addition of $1 \%$ of Ag. Impact toughness of the alloys increased from $9.4 \mathrm{~J}$ to $10.1 \mathrm{~J}$. The impact toughness of Sn$1 \mathrm{Cu}-1 \mathrm{Ni}$ is found to be increased by $3.1 \%$ with the addition of $1 \%$ by wt. Ag. A comparison of hardness, shear strength and impact toughness between Sac105, SCN110, SCN110-1Ag is shown in the figure 5, figure 6 and figure $7 . \mathrm{Sn}-1 \mathrm{Cu}-1 \mathrm{Ni}-1 \mathrm{Ag}$ is found to be having good improved shear strength and impact toughness than $\mathrm{Sn}-1 \mathrm{Cu}-1 \mathrm{Ni}$. 


\section{Acknowledgements}

This research did not receive any specific grant from funding agencies in the public, commercial, or not-for-profit sectors.

\section{REFERENCES}

[1] Schwartz, MM.: Soldering: Understanding the basics. 1st edition. ASM International, USA, 2014

[2] Manko, HH.: Solder and Soldering. 2nd edition. New York : McGraw-Hill, 1979

[3] Cheng, S., Huang, C-M., Pecht, M.: A review of lead-free solders for electronics applications. Microelectronics Reliability, 2017, 10.1016/j.microrel.2017.06.016

[4] European Parliament. Proposal for a Directive of the European Parliament and of the Council on Waste Electrical and Electronic Equipment and on the restriction of the use of certain hazardous substances in electrical and electronic equipment. COM 2000;:347

[5] Gain, AK., Zhang, L.: J. Mater. Sci. Mater. Electron., vol. 27, 2016, p. 781

[6] Gain, AK., Chan, YC., Yung, KC., Sharif, A., Ali, L.: Mater. Sci. Eng. B, vol. 162, 2009, p. 92

[7] Chang, C., Chuang, TH., Feng, LP., Tsao, LC.: Mater. Des., vol. 32, 2011, p. 4720

[8] Leong, L., Fang, CJ., Chu, CP.: J. Mater. Sci. Mater. Electron., vol. 22, 2011, p. 1443

[9] Chen, S., Kaoa, CR.: J. Alloys Compd., vol. 520, 2012, p. 244

[10] Jayesh, S., Elias, J.: Met. Mater. Int., 2019, https://doi.org/10.1007/s12540-01900305-3

[11] Elias, JSJ.: Lett. Mater., vol. 9, 2019, no. 2, p. 239

[12] Jayesh, S., Jacob, E.: Int. J. Simul. Multisci. Des. Optim., 10.1051/smdo/2019013 